\title{
DO ESTADO LIBERAL AO ESTADO SOCIAL E DEMOCRÁTICO DE DIREITO: ANÁLISE DO SURGIMENTO DO ATIVISMO JUDICIAL
}

\author{
FROM TO THE LIBERAL STATE INTO THE SOCIAL AND DEMOCRATIC \\ STATE OF LAW: ANALYSIS OF THE EMERGENCE OF JUDICIAL ACTIVISM
}

\author{
Alexandre Luna da Cunha ${ }^{1}$ \\ Paula Zambelli Salgado Brasil ${ }^{2}$
}

\begin{abstract}
RESUMO
Este artigo analisará a relação entre o Poder Judiciário e a efetivação dos direitos sociais e, por consequência, o propalado ativismo judicial. Mais especificamente, o artigo responderá à seguinte indagação: como o papel do Poder Judiciário se modificou com o desenvolvimento dos modelos de Estado? O artigo desenvolverá seu problema analisando a função do Poder Judiciário em cada um destes modelos de Estado de Direito: o Liberal, o Social (em que pese tal Estado não ter sido cabalmente implementado no Brasil) e o Democrático. Para tanto, levará em conta a relação entre os poderes republicamos instituídos, a movimentação social pela conquista de direitos e a positivação de uma nova geração de direitos. O ativismo Judicial será analisado como consequência prática de um novo constitucionalismo, mais pautado na efetivação de direitos sociais delineados nos textos constitucionais de cunho democrático.
\end{abstract}

Palavras-chave: Estado liberal, Estado social, Estado democrático, Ativismo judicial

\begin{abstract}
This article will examine the relationship between the judiciary and the effectiveness of social rights and, consequently, the vaunted judicial activism. More specifically, the article will answer the following question: the role of the judiciary has changed with the development of state models? Article develop their problem by analyzing the function of the judiciary in each of these rule of law models: the Liberal, Social (in spite of that State have not been fully implemented in Brazil) and the Democratic. To do so, take into account the relationship between the established powers republish, social movement for the conquest of rights and assertiveness of a new generation of rights. The "Judicial activism" is analyzed as the practical consequence of a new constitutionalism, more guided in the realization of social rights outlined in the constitutions of democratic character.
\end{abstract}

Keywords: Liberal state, Social status, Democratic state, Judicial activism

\footnotetext{
${ }^{1}$ Doutorado em Direito pela Universidade Presbiteriana Mackenzie, São Paulo, (Brasil). Professor de Direito pela Fundação Getúlio Vargas - FGV, São Paulo, (Brasil). E-mail: lunadacunha@yahoo.com.br

2 Doutoranda em Direito Político e Econômico na Universidade Presbiteriana Mackenzie, São Paulo, Brasil. Professora pela Universidade Nove de Julho - UNINOVE, São Paulo, (Brasil). E-mail: pzsb@terra.com.br
} 


\section{INTRODUÇÃO}

A teoria jurídica hegemônica nos países de Direito codificado propugna pela a ideia de que o Direito e sua aplicação devem ser fundados na subsunção do fato à norma, erigida e proclamada pelo Poder Legislativo como o Direito (positivo) de uma nação. Esta é uma concepção do Direito presente em nosso cotidiano jurídico e que seus precedentes históricos no Estado Liberal, implementado na Europa e América do Norte após as revoluções burguesas. Para fins metodológicos, teremos como base de análise a Revolução Francesa e os modelos jurídicos adotados nos países da Europa central, já que o Direito Brasileiro se consolidou a partir destes últimos ${ }^{3}$.

Esse artigo visa refletir acerca da relação entre o Poder Judiciário e a efetivação dos direitos sociais e, por consequência, da determinação e implementação de políticas públicas; ou, em termos pragmáticos, pretendemos responder à seguinte indagação: qual o papel do Poder Judiciário e como este papel se modificou ao longo do desenvolvimento dos modelos de Estado de Direito.

Assim, trabalharemos a temática do Poder Judiciário em cada um dos Estados de Direito: o Liberal, o Social (em que pese tal Estado não ter sido implementado no Brasil) e o Democrático.

Abordaremos, por fim, o propalado "ativismo Judicial”, como configuração prática de um novo constitucionalismo, mais pautado na efetivação dos anseios (sociais e de justiça) delineados no texto constitucional.

\section{O PODER JUDICIÁRIO NO CONTEXTO DO ESTADO MODERNO}

É necessário destacar, em especial, a análise de Alexis de Tocqueville (1998, p. 82) acerca de estruturação de poderes na República dos Estados Unidos da América, que assim se manifestou:

\footnotetext{
${ }^{3}$ Em especial, baseado em BONAVIDES, Paulo. Do Estado Liberal ao Estado Social. 7.ed. 2.tir. São Paulo: Malheiros, 2004.
} 
“O que o estrangeiro com maior dificuldade compreende nos Estados Unidos é a sua organização judiciária. Por assim dizer, não há ocorrência política para a qual não ouça ele ser chamada a autoridade do juiz; e conclui, à vista disso, naturalmente, que o juiz é, nos Estados Unidos, uma das primeiras forças políticas. Depois, quando passa a examinar a constituição dos tribunais, só descobre nela, a princípio, atribuições e hábitos judiciários. Aos seus olhos, o magistrado nunca parece introduzir-se nos negócios públicos a não ser por acaso; mas esse mesmo acaso repete-se todos os dias."

Em um primeiro momento cumpre-nos levantar a explanação de Tocqueville sobre a perplexidade de um estrangeiro sobre o modo de estruturar e organizar o Estado e o Poder Judiciário nos Estados Unidos. Isso, a princípio pode causar alguma estranheza, mas nos remete a darmos atenção aos ensinamentos de Herbert L. A. Hart (1994) sobre a posição de um estudioso frente ao seu objeto de estudo. No caso, a posição de um estudioso do ordenamento jurídico num Estado Moderno, e seu aparato para fazer-se valer na prática, por meio das Instituições judiciais.

Para tanto, Herbert L. A. Hart alerta que, a forma de entender o objeto de um estudo vai depender da posição do intérprete em relação ao dito objeto: se inserido na realidade típica do ordenamento, tende a aceitar e reproduzir os postulados implícitos, notadamente os mitos e ideologias do sistema (jurídico) que estruturam seu objeto. Neste sentido, cumpre lembrar que buscamos realizar uma análise crítica da teoria jurídica, do Sistema judiciário e seu papel, mas estamos inseridos no sistema. Se situado fora do referido objeto, o jurista/intérprete tende a reconstruir sua argumentação a partir das hipóteses e dos pressupostos do sistema jurídico que ele opera, criticando e apontando suas incongruências ${ }^{4}$.

\footnotetext{
${ }^{4}$ A análise da teoria de Herbert L. A. Hart está baseada na leitura direta de sua obra $O$ conceito de Direito que aponta para o fato de que, muitas vezes, os limites naturais da linguagem impedem que o direito se expresse, sempre, por meio de enunciados unívocos, gerando a necessidade de o interprete buscar (dentro do sistema) a complementação do significado de termos não precisos. Isso determina que o direito é um sistema aberto, em que as questões mais difíceis (hard cases) são caracterizadas por textura aberta. Nesses casos difíceis, a "indeterminação do sentido das regras seria insolúvel, neste aspecto a resposta deveria ser dada pelo juiz com recurso ao poder discricionário. Isso caracterizaria a possibilidade, nos casos difíceis, de criação de direito pelo Judiciário - nos casos paradigmáticos se recorreria às regras jurídicas institucionalizadas". Como suporte à interpretação da teoria de Herbert L. A. Hart, dentre outros, foi consultada a obra de Leonel Severo Rocha, Introdução de "Paradoxos da auto-observação. Percursos da teoria jurídica contemporânea. Ambas as obras estão referenciadas ao final do artigo.
} 
Assim, utilizando os ensinamentos de Herbert L. A. Hart, sobre a posição do intérprete no sistema jurídico, para estudar como são tomadas as decisões judiciais nas cortes superiores, Marie-Clarie Ponthoreau (2012, pp. 7-8) demonstra que há uma oposição epistemológica entre os sistemas da common law e a civil law e, consequentemente, há dois contextos diferenciados para se chegar a uma resolução de um conflito: o da tomada de decisão, propriamente dita, e o da descoberta de justificação e racionalidade da dita decisão, com a argumentação utilizada para a motivação da sentença. Isso porque os sistemas da common law por um lado, e o romano germânico, por outro, dependem da tradição e culturas jurídicas dos respectivos sistemas, que podem gerar formas muito diferentes de atuação de um juiz, pois o método indutivo, empíricoprático (pragmático) é típico dos Estados anglossaxônicos. Por outro lado, o método dedutivo e sistemático, que busca reproduzir uma certa lógica, racionalidade e coerência do sistema romano-germânico ${ }^{5}$.

O Brasil, como Estado cujo Direito (positivo) é estruturado num sistema jurídico fechado, legalista e codicista, tipicamente romano-germânica, está disposto num acervo pretendidamente intemporal, que culmina em proposições gerais que se manipulam dedutivamente. Nesses sistemas, há uma certa pretensão de totalidade em sua positivação - cuja tarefa deverá ser desenvolvida, precipuamente, pelo Poder Legislativo, a quem incumbe como função típica a inovação da ordem jurídica, por meio das leis.

Já a formulação clássica (e liberal) do Poder Judiciário foi delineada pela ideia de neutralidade política deste poder, isso porque na modernidade, com o monopólio estatal da criação e da aplicação do Direito, a decisão judicial deriva da aplicação de uma norma preexistente a um caso concreto, conforme Paulo Abrão Pires Jr (2000, p. 135):

\footnotetext{
3 Josef Esser, há quase sessenta anos, ao trabalhar a questão do uso de princípios e normas na elaboração jurisprudencial da common law, ensina que se reconhece aos tribunais a autoridade legal para criação de princípios e regras, em que os conceitos jurídicos são desenvolvidos de modo puramente heurístico de forma que, uma vez fixados os precedentes judiciais, assumem estes a condição de paradigmas, chaves, para a compreensão jurídica do problema e a elaboração de uma solução justa sobre o caso. Na common law, portanto, o processo de descobrimento do sistema pode ser assim descrito: um método de formação de normas afiançado pela tradição, onde o princípio forma o ponto de partida de um desenvolvimento jurisprudencial aberto, método que, graças à existência de um acervo de regras técnicas sobre a elaboração de uma norma, parte de precedentes obrigatórios e garante a continuada concreção das máximas, em uma estrutura linear, uma instrução exata. Verificar obra referenciada ao final, Principio y norma en la elaboración jurisprudencial del derecho privado.
} 
"Se o Estado surge como um terceiro mediador dos conflitos para o estabelecimento da paz, essa leitura de neutralidade frente aos conflitos é repassada para o Poder Judiciário, a quem caberá julgá-los em nome do poder estatal. A neutralidade do juiz é uma consequência da neutralidade do Estado, ou melhor, o sistema de tribunais afirma a neutralidade estatal na vida social"'.

Esta neutralização do Judiciário e a predominância do Legislativo é fruto dos princípios da legalidade e o da subsunção racional-formal. Montesquieu (2004, p. 202), um dos principais teóricos da separação dos poderes, demonstra sua preocupação com o excesso de poder concentrado nas mãos dos magistrados do Antigo Regime, afirmando que,

"não haverá também liberdade se o poder de julgar não estiver separado do poder legislativo e do poder executivo. Se estivesse ligado ao poder legislativo, o poder sobre a vida e a liberdade dos cidadãos seria arbitrário, pois o juiz seria legislador. Se estivesse ligado ao poder ao poder executivo, o juiz poderia ter a força de um opressor".

Assim, o Poder Judiciário foi concebido sob a perspectiva deste direito pretensamente completo, coerente e hierárquico, com princípios bem delineados para a resolução de (possíveis) antinomias. Aos juízes caberia um simples raciocínio silogístico: cuja premissa maior, universal, está constituída pelo enunciado da lei; a premissa menor, particular, pelo enunciado dos fatos, do qual se infere como conclusão um enunciado que aplica ao descrito na premissa menor a qualificação jurídica contida na maior, em outras palavras, a subsunção dos fatos às normas legais. Assim, "com a força lógica do silogismo se afiançava a ideia de que a atividade jurisdicional não constituía obstáculo para a realização dos ideais de certeza e segurança jurídica”, conforme Juan Ramón Capella (1997, p. 145).

Assim, como verifica José Eduardo Faria (1995, pp. 29-30), a atividade judicial era entendida:

"como simples administração da lei por uma instituição tida como 'neutra', 'imparcial' e 'objetiva', ficando o intérprete/aplicador convertido num mero técnico do direito positivo. Como o que importa não é a explicação, a compreensão e a orientação dos comportamentos jurídicos, e sim a tipificação e sistematização de situações normativas hipotéticas, ao agir de modo técnico, isto é, sem preferências valorativas e imune às paixões políticas, o juiz não se limita a atuar tendo em vista apenas a consecução das garantias formais, da certeza jurídica e do império da lei, postulados fundamentais do modelo/paradigma liberal burguês do Estado de Direito; ele também desempenha o papel profissional 'competente' na integração dos atores considerados 'disfuncionais' da vida social. Sua neutralidade e sua 
imparcialidade, conjugadas com uma hermenêutica positivista que o obriga a interpretações restritivas e objetivas dos códigos, convertem-se em condição básica para a legitimação de uma concepção específica de ordem e segurança. Trata-se, pois, de uma concepção passiva de instituição judicial" (grifo nossos).

A teoria da separação dos poderes "foi concebida num momento histórico em que se pretendia limitar o poder do Estado e reduzir ao mínimo sua atuação. Mas a evolução da sociedade criou exigências novas, que atingiram profundamente o Estado", conforme assevera Dalmo de Abreu Dallari (2009, p. 186). E, dentre as consequências de tais transformações, especificamente, houve mudanças no papel que o Poder Judiciário deve desempenhar. Se, nas primeiras configurações dos Estados de Direito não havia interferência estatal nos assuntos privados, o Estado Social caracterizar-se-á pelo intervencionismo do Estado nas relações sociais. $^{6}$

As transformações próprias do período do Estado Social exigiram, de certa forma, algumas modificações das posturas dos operadores jurídicos e que isso nem sempre foi possível ou ocorreu de forma tranquila, até mesmo porque "o primado básico do Estado Liberal se mantém, a despeito de o Estado ter-se transformado em Intervencionista, qual seja: a separação entre os trabalhadores e os meios de produção, gerando mais-valia, de apropriação privada do capital", como destacam Lenio Luis Streck e José Luiz Bolzan Morais (2000, p. $58)$.

\section{NOVA CONCEPÇÃO DO PODER JUDICIÁRIO NA TRANSIÇÃO DO ESTADO LIBERAL PARA O ESTADO SOCIAL DE DIREITO}

As lutas sociais foram decisivas para a aceleração da passagem do Estado Liberal para o Estado Social, como bem destaca Boaventura de Sousa Santos (1995, p. 165): a "igualdade dos cidadãos perante a lei passou a ser confrontada com a desigualdade da lei perante os cidadãos", forçando o delineamento de um Estado: "ativamente envolvido na gestão dos conflitos e concertações entre classes e grupos sociais, e apostado na minimização possível das desigualdades sociais".

\footnotetext{
${ }^{6}$ Importante ressaltar a formulação feita por Lenio Luiz Streck e José Luis Bolzan Morais quanto ao não intervencionismo do Estado Liberal: "o grau zero de intervenção é ideal nunca alcançado, pois sempre houve políticas estatais de algum tipo ou, porque, como se percebe o Estado liberal requer qualidades e pressupostos igualitários, além de uma competição equilibrada" na obra referenciada ao final, Ciência Política e Teoria Geral do Estado.
} 
Neste contexto, a lei passa a ser a possibilidade concreta de intervenção estatal, o que levou à uma modificação do equilíbrio na correlação de forças dos poderes estatais. Se, no período anterior, o Poder Legislativo assumia uma certa preponderância sobre os demais, no Estado Social esta preponderância será assumida pelo Poder Executivo, como destacam Lenio Luis Streck e José Luiz Bolzan Morais (2000, p. 65): "o Princípio da Legalidade e o da Separação de Poderes foram mantidos tão somente sob o aspecto formal, tendo sido, na prática, ab-rogados em razão da intensa atividade legislativa praticada pelo Executivo. "

Assim, verifica-se que o Princípio da Legalidade, neste período, foi mantido apenas numa perspectiva formal, abrindo brechas para que o Poder Judiciário assumisse uma postura mais independente, em detrimento de sua neutralização, própria do Estado Liberal. Boaventura de Sousa Santos (1996, p. 35-44) descreve o dilema vivido pelo Poder Judiciário neste período:

\begin{abstract}
"Se continuassem a aceitar a neutralização política vivida no período anterior, preservando no mesmo padrão de desempenho clássico, reativo, de microlitigação, poderiam certamente continuar a ver reconhecida pacificamente pelos outros poderes do Estado a sua independência, mas falo-iam correndo o risco de se tornarem socialmente irrelevantes (...) se aceitassem a sua cota-parte de responsabilidade política na atuação promocional do Estado (...) corriam o risco de entrar em competição com os outros poderes e de, como poder mais fraco, começar a sofrer as pressões do controle externo, quer por parte do Poder Executivo, quer por parte do Poder Legislativo."
\end{abstract}

O Estado Social passou a exercer o papel de fomentador das garantias sociais, assumindo assim, "a gestão da tensão que ele próprio cria, entre justiça social e igualdade formal; dessa gestão são incumbido, ainda que de modo diferente, todos os órgãos e poderes do Estado", conforme afirma Boaventura de Sousa Santos (1996, p. 35-44). Nesse aspecto, o Poder Judiciário que, após a consagração dos direitos sociais (de segunda dimensão) no texto constitucional, passa a exercer uma prestação positiva, ou seja, um papel mais interventivo junto às necessidades sociais. Diferentemente do que ocorria no Estado Liberal, que cumpria o papel de garantidor dos direitos civis (de primeira dimensão), por intermédio da sua nãointervenção junto à sociedade.

Nos anos de 1970, o Estado Social passa a ser alvo de diversas crises, inicialmente pautadas pelas discussões acerca da questão do financiamento do Estado - incapacidade de arrecadação dos impostos, por parte do Estado, para a realização das demandas sociais crescentes e pungentes, com a estagnação das economias mundiais, gerando uma crise 
econômica de produção por um lado e, por outro, o consequente aumento das despesas sociais, desequilibrando a relação de despesas e receitas das contas públicas. Em continuidade, já nos anos 80, torna-se clara a complexidade da crise, que passa a atingir outros dois aspectos do Estado Social: o ideológico e o filosófico.

A crise ideológica pode ser entendida como a crise da legitimação do Estado Social, na medida em que a relação existente entre Estado e sociedade civil é tão distante que esta não participa na execução das atividades daquele, criando uma situação de oposição entre as duas esferas. A sociedade espera a resolução de seus problemas, por meio de políticas do Estado, mas ao mesmo tempo, não reconhece as medidas governamentais suficientemente legítimas para suas necessidades, como bem ensina Pierre Rosanvallon (1997, p.15 e p. 30, respectivamente):

\begin{abstract}
"A dúvida sobre o Estado-Providência não pode, portanto, ser entendida tão somente do ponto de vista da regulação dos equilíbrios econômicos que o regem. Não é apenas a extensão do Estado ou o peso das despesas sociais que está em causa. Esta dúvida manifesta um abalo muito mais profundo: são as relações da sociedade com o Estado que são questionadas". Assim, os impostos "aumentaram sem que ocorresse o mínimo elemento simbólico de reformulação do compromisso social. A redução das desigualdades revela-se, assim, menos legítima: não foi acompanhada por uma vontade ou por uma palavra da sociedade sobre si mesma".
\end{abstract}

A crise filosófica é entendida como consequência natural da crise ideológica como destaca José Luiz Bolzan Morais (1999, p. 61):
e "atinge exatamente os fundamentos sobre os quais se assenta o modelo do bem-estar. Esta crise aponta para a desagregação da base do estado de Bem- Estar, calcada na solidariedade, impondo um enfraquecimento ainda maior no conteúdo tradicional dos direitos sociais, característicos deste Estado a partir de uma relação clientelista que irá se construir entre o cidadão e o Estado".

Na busca de possíveis soluções à crise, ganha destaque, nos mesmos anos 80, o projeto neoliberal, que diante da incapacidade de reformulação do Estado Social, propõe um retorno à não intervenção estatal. Uma das mais severas consequências desta crise no âmbito dos poderes estatais é a perda do monopólio de suas funções: o monopólio de produção do Direito é quebrado pelo surgimento de outros focos de elaboração legislativa (surgimento da lex mercatoria, por exemplo), que desembocam numa espécie de caos normativo ou perda de unidade do sistema. Para Boaventura de Sousa Santos (1996, p. 37), a perda de unidade do 
sistema é decorrência do projeto neoliberal de desregulamentação da economia, e este é um processo contraditório na medida em que

"depois de décadas de regulação, a desregulamentação só pode ser levada a cabo mediante uma produção legislativa específica e por vezes bastantes elaborada. Ou seja, a desregulamentação significa em certo sentido uma reregulamentação e, portanto, uma sobrecarga legislativa adicional."

No âmbito do Judiciário, a crise do monopólio estatal da resolução dos conflitos é sentida, em parte, pelo excesso de litígios judiciais, pois o aumento da litigância engendra uma queda do desempenho jurisdicional, como apontado por Boaventura de Sousa Santos (1996, p. 38): "a massificação da litigação desse origem a uma judicialização rotinizada, com os juízes a evitar sistematicamente os processos e os domínios jurídicos que obrigassem a estudo ou decisões mais complexas, inovadoras ou controversas".

Diante das dificuldades do Poder Judiciário, a própria sociedade busca outras formas mais rápidas e eficazes de resolução dos conflitos e, consequentemente, de acesso à justiça. $\mathrm{Na}$ realidade, os novos focos de produção legislativa institucionalizam os modos alternativos de resolução de conflitos. Além disso, temos os tribunais rodeados de várias outras situações que agravam seu desempenho junto à sociedade, como o surgimento de litígios complexos - a partir da terceira revolução tecnológica e do aparecimento dos direitos de terceira geração, em especial nas áreas de direito do consumidor e meio-ambiente — demandando um maior aprofundamento teórico e prático que não foi alcançado, principalmente, na análise de Boaventura de Sousa Santos (1996, p. 38) devido a "impreparação dos magistrados, combinada com a sua tendência de se refugiarem nas rotinas e no produtivismo quantitativo, fez com que a oferta judiciárias fosse nesses litígios altamente deficiente".

Se, no início do Estado Social os tribunais tiveram que decidir entre uma política de maior intervenção junto à sociedade, opondo-se muitas vezes aos outros poderes, ou uma postura mais de neutralidade, como no Estado Liberal; na crise do Estado Social, o dilema vivido pelos tribunais é muito mais profundo. Isto porque, da sua interferência junto aos casos mais complexos depende a sobrevivência da confiança no Judiciário, e não mais apenas um debate sobre as definições das políticas sociais as serem adotadas, conforme destaca Paulo Abrão Pires Jr. (2000, p. 364):

O fato é que onde houver direito a ser reivindicado, haverá de existir alguém ou algum mecanismo que o distribua. Com a perda de espaço do Estado, o 
Poder Judiciário, como uma instituição deste Estado, pode ver suas funções originais readequadas ou abolidas, isso dependerá da própria (re)ação de seus membros. Pois, na medida em que o Poder Judiciário deixa-se enfraquecer, corrobora no enfraquecimento do Estado e isto, por sua vez, aprofunda a crise do Poder Judiciário, num vicioso círculo. Cada vez que o Poder Judiciário não cumpre seu papel no Estado Democrático de Direito, colabora com sua própria crise. Cada vez que deixa de assegurar um direito alegando a ordem econômica internacional, cada vez que se autodenomina incapaz de defender a Constituição, cada vez que abre mão de barrar as investidas do Executivo e do Legislativo, cava sua própria cova.

\section{SURGIMENTO DO ATIVISMO JUDICIAL, NO ESTADO DEMOCRÁTICO DE DIREITO}

O Direito nos países da Europa Central sofreu muitas modificações importantes, ocorridas principalmente após a implementação do Estado Social. Entretanto, nos países periféricos, como o Brasil, onde a cultura herdada dos regimes ditatoriais ainda está muito enraizada, deparamo-nos com práticas que negam o crescente protagonismo do Judiciário no Estado Democrático de Direito.

Ao falarmos de América Latina, especificamente o Brasil, estamos falando num país de imensas desigualdades sociais, sem distribuição de renda e com forte tradição de regimes autoritários. Após um longo período de regime militar ditatorial, buscamos, com a promulgação da Constituição Federal de 1988, que consagrou uma série de direitos e garantias fundamentais, o processo de implementação da democracia.

Entretanto, a simples existência de uma Constituição calcada em bases democráticas não é a garantia da implementação de um modelo democrático. É preciso levar em consideração, também, a ressalva de Boaventura de Sousa Santos (1996, p. 44) de que os "países periféricos e semiperiféricos viram-se na contingência de consagrar constitucionalmente ao mesmo tempo os direitos que nos países centrais tinham sido consagrados sequencialmente, ao longo de um período de mais de um século".

Para além dos aspectos de ordem cultural, a inefetividade de diversos dispositivos em nossa Constituição tem seus principais motivos na política implementada em nosso país desde o período de redemocratização. Se levarmos em consideração o fato de não ter existido, substancialmente, no Brasil, um "Estado Social”, é possível compreender que a abertura para um regime democrático de garantia dos direitos fundamentais só poderia ter existido mediante 
um Estado forte, interventor. Entretanto, o que assistimos nos últimos tempos é justamente o contrário, ou seja, a adoção de políticas neoliberais de diminuição do Estado e enfraquecimento de sua capacidade de intervenção em nome da liberdade de mercado. A minimização do Estado, com o neoliberalismo, consolidou-se como um modelo econômico-social, principalmente após a crise do Estado Social; a questão principal é destacada por Lenio Luiz Streck (2000, p. 24) que afirma: "a minimização do Estado em países que passaram pela etapa do Estado Providência ou welfare state tem consequências absolutamente diversas da minimização do Estado em países como o Brasil, onde não houve o Estado Social".

O Direito, que deveria ser visto como um instrumento de transformação social, não consegue ter um papel mais interventor no sentido de assegurar a efetividade de nossa Constituição. Muito pelo contrário, a inefetividade constitucional não parece afetar/preocupar a maior parte de nossos operadores jurídicos. Muitas causas podem ser atribuídas a esta apatia, Boaventura de Sousa Santos (1996, p. 45) elencou seis delas, segundo o autor, as mais significativas para a caracterização deste quadro.

Inicialmente, o conservadorismo dos magistrados, incubados em faculdades de Direito intelectualmente anquilosadas, dominadas por concepções retrógradas da relação entre direito e sociedade; depois, o desempenho rotinizado assente na justiça retributiva politicamente hostil à justiça distributiva e tecnicamente despreparado para ela; em terceiro plano, uma cultura jurídica "cínica" que não leva a sério a garantia dos direitos constitucionais, vendo nelas meras declarações programáticas de conteúdo utópico; em quarto, uma organização judiciária deficiente com carências de recursos humanos, técnicos e materiais, com um Poder Judiciário tutelado por um Poder Executivo e, por fim, um direito processual hostil e antiquado.

Essas características configuram uma crise vivida pelo Direito (e sua teoria) em nosso país, em que "ocorre uma desfuncionalidade do Direito e das Instituições encarregadas de aplicar a lei. O Direito brasileiro e a dogmática jurídica que o instrumentaliza está assente em um paradigma liberal-individualista que sustenta essa desfuncionalidade". O Direito e sua teoria sofreram muitas modificações importantes, ocorridas principalmente após a implementação e posterior decadência do Estado Social, que acabaram por distanciá-lo das propostas de teorias de direito tradicionais, as quais não são suficientes para dar conta da complexidade teórica e das novas práticas jurídicas que se desenvolveram. Nas palavras de Eduardo Ribeiro Moreira (2008, pp. 261-277): 
"Em primeiro lugar, é oposto ao positivismo, naquilo que este mais se apoiava. Como todos sabem a estrutura do positivismo se sustentava pela separação do direito com a moral e a política (e porque não em relação à economia, que não ocupava o papel que ocupa hoje). Em segundo lugar, também se afasta das inconsistências do jusnaturalismo e nos poucos pontos que poderia ser confundido com ele, pois o neoconstitucionalismo é fundado em propostas de incremento de racionalidade, como a festejada ponderação. Finalmente e em terceiro lugar, o realismo jurídico e a sua dimensão sociológica não ficam descurados em uma proposta que age sobre o direito útil".

A politização da Justiça ${ }^{7}$, entendida como ativismo coordenado na realização de políticas públicas, não representava uma realidade premente antes da atual Constituição Brasileira, sendo esporádica e não significativa, a intervenção do Judiciário nas temáticas respeitantes à comunidade. O Judiciário, como visto, mantinha-se inerte, ligado à justiça retributiva. Apenas algumas decisões em ações populares (com o alargamento dos conceitos de patrimônio e de lesividade por parte dos juízes) e na nascente ação civil pública (já na década de 1980) permitiam falar em uma atividade judiciária distributiva no Brasil ${ }^{8}$.

Assim, e talvez de maneira não intencional, numa busca da superação do quadro delineado acima, ensina Hermes Zaneti Junior (2014, p. 140) que a Constituição brasileira de 1988 potencializou e implementou ao máximo o papel do Judiciário e do direito, fundando um novo paradigma: o do Estado Democrático de Direito.

Trouxe para a nossa realidade institutos como o mandado de segurança coletivo, o mandado de injunção, a arguição de descumprimento de preceito fundamental, desvinculou o Ministério Público Federal das tarefas de defesa dos interesses da União (art. 129, IX, da CF/88), criando a Advocacia Geral da União, e subdividiu as competências dos tribunais, de forma a garantir ao Supremo Tribunal Federal a defesa "precípua" do Texto Constitucional. E continua o autor: "com aumento da legitimidade nas ações de controle de constitucionalidade das normas, criação de novos writs e recepção das ações coletivas para a tutela dos direitos coletivos lato sensu". Essas radicais

\footnotetext{
${ }^{7}$ Utilizando o conceito de Ferreira Filho, "entende-se por judicialização da política a tendência a atribuir, ou submeter, aos tribunais judiciários a decisão de mérito a res- peito de ações administrativas ou normas obrigatórias. Ou seja, decisões 'políticas', porque concernentes ao interesse da comunidade” presente no artigo A Constituição de 1988 e a judicialização da política referenciado ao final.

${ }^{8}$ Revela-se estritamente correta a afirmação de Ferreira Filho de que "incontestavelmente [...] foi a Constituição de 1988 que, consciente ou inconsciente- mente, determinou ampla e visível judicialização da política". Antes da Constituição de 1988, era negligenciável a judicialização da política no Brasil, embora nalguns pontos ela já aparecesse. Não por obra do Supremo Tribunal Federal que, no tocante ao controle de constitucionalidade, sempre assumira uma posição de contenção, mas devido à atuação de juízes e tribunais estaduais" presente no artigo A Constituição de 1988 e a judicialização da política referenciado ao final.
} 
mudanças transformaram o papel do Judiciário que, de espectador passivo no paradigma legalista, passou a ser chamado a opinar em questões de dimensão política e social antes jamais imaginadas, quer em razão dos novos direitos materiais surgidos no quadro da nova Carta Magna, quer em razão da própria dimensão alargada dos instrumentos processuais postos à disposição da cidadania para garantir a efetividade desses direitos.

Nesse novo paradigma, num giro de importância, o Judiciário tem sua função reformulada e sua influência se sobressai à do Executivo e à do Legislativo. Não se pode negar que o princípio da legalidade perdeu força em face da Constituição. A ideologia imanente ao atual paradigma não se sustenta naquele princípio, já que ele cedeu espaço aos enunciados constitucionais, os quais, aliás, condicionam a própria legitimidade da lei. Relativiza-se o princípio da legalidade e atinge-se, na sua plenitude, o princípio da constitucionalidade, como destacam, Lúcio Delfino e Fernando Rossi (2014, p. 4).

Não faltam críticos da discricionariedade judicial exacerbada, que se distingue, nitidamente, das discricionariedades legislativa e administrativa, correspondendo à liberdade de escolha que se defere ao juiz diante de possibilidades exegéticas consistentes. Floresce ela no espaço que os balizamentos normativos autorizam o julgador a se movimentar, porém com a sensível diferença de que o controle, nesse caso, compete ao próprio órgão ao qual foi deferido o poder discricionário, o que não significa que possa, em harmonia com o sistema, tudo fazer.

Para Elival Ramos (2010. p. 310) o exercício da função jurisdicional para além dos limites impostos pelo próprio ordenamento que incumbe, institucionalmente, ao Poder Judiciário fazer atuar, resolvendo litígios de feições subjetivas (conflitos de interesse) e controvérsias jurídicas de natureza objetiva (conflitos normativos). Essa ultrapassagem das linhas demarcatórias da função jurisdicional se faz em detrimento, particularmente, da função legislativa, não envolvendo o exercício desabrido da legiferação (ou de outras funções não jurisdicionais) e sim a descaracterização da função típica do Poder Judiciário, com incursão insidiosa sobre o núcleo essencial de funções constitucionalmente atribuídas a outros Poderes. Se no positivismo clássico a interpretação se submete à vontade do legislador, dando ensejo ao fenômeno do passivismo judiciário, a consequência do pragmatismo e do moralismo jurídico é o ativismo subjetivista do intérprete-aplicador; amplo e explícito no primeiro caso, circunscrito e implícito, no segundo. 
Já no positivismo moderado ou renovado, o que prevalece é a vontade da lei, não no sentido de um pressuposto prévio, pronto e acabado, que o juiz tenha que meramente aderir, mas no de que o texto normativo objeto de exegese contém algo de objetivo, que não pode ser desconsiderado, embora constitua apenas um limite no trabalho de construção da norma de decisão, em que também conta (embora não com o mesmo peso) a vontade do intérprete. Se as decisões judiciais não são elaboradas livremente e se, tampouco, a discricionariedade do juiz é tão ampla quanto à do legislador, é nos limites substanciais que o próprio direito a aplicar lhe impõe (e não nos procedimentos formais que deve seguir para fazê-lo - due process of law) que se hão de buscar os critérios para a aferição da existência ou não de ativismo judiciário.

Para Miguel Carbonnel (2008, p. 197-208) ${ }^{9}$ os diversos fenômenos podem ser observados desde o início do século XX, contudo, quando há a junção de três desses fenômenos, concomitantemente, acabam por constituir o que se denomina "neoconstitucionalismo": o primeiro é a inserção de diversos direitos fundamentais nos textos constitucionais, com mandados substantivos, que imponham a concretude material dos mesmos; o segundo é o surgimento de uma nova forma de agir judicial, entendida como "ativismo judicial", em que as cortes superiores buscam consolidar, materialmente, os ditames constitucionais ${ }^{10}$ e, por terceiro elemento, a criação de um arcabouço teórico, com a teorização de uma hermenêutica constitucional, que além de procurar compreender o texto constitucional e a fundamentar as novas práticas jurisprudenciais, ajudam a criá-las ${ }^{11}$.

\footnotetext{
"Es obvio que ya existían textos con mandatos constitucionales sustantivos desde principios del siglo XX (por ejemplo la Constitución mexicana de 1917 o la ale- mana de la Weimar de 1919). También es verdad que las prácticas jurisprudenciales anteriores a la Segunda Guerra Mundial habían desplegado ciertas dosis de activismo judicial que se parecen a las que actualmente observamos en países con incipientes tradiciones neoconstitucionalistas. Probablemente se pueden rastrear postulados neopositivistas desde los años 30 del siglo XX. Son elementos que sin duda alguna se encuentran en la raíz histórica y política del neoconstitucionalismo; pero lo que resulta interesante del cuadro neoconstitucional que tenemos a la vista en los primeros años Del siglo XXI es el conjunto, la combinación de los tres elementos que he mencionado. Y todavía más que eso: lo novedosos son sus efectos, es decir, la observación del Estado constitucional de derecho en funcionamiento."
}

Para Willis Santiago Guerra Filho (1997, p. 37):

"Do Judiciário de hoje, não é de se esperar uma posição subalterna frente a esses outros poderes, a quem caberia a produção normativa. O juiz não há de se limitar a ser apenas, como disse Montesquieu, la bouche de la loi, mas sim la bouche du droit, isto é, a boca não só da lei, mas do próprio Direito". 


\section{CONCLUSÕES}

Na sociedade brasileira atual, em que ao aumento diuturno do grau de complexidade das relações sociais e jurídicas, o Poder Judiciário, como um dos poderes do Estado, tem que enfrentar o crescimento dos desafios que lhe são impostos sem que haja proporcional crescimento da construção teórica que permita a superação desses desafios.

Se há um constante clamor por reforma no Poder Judiciário, é porque há crise(s) no/do Poder Judiciário. E há o agravamento dessa crise quando as análises, desde as diversas perspectivas adotadas para tal, ao invés de trabalharem suas causas, acabam por escamotear a temática por detrás dessas questões: se o Poder Judiciário é responsável por "dizer o direito" e, com isso, "realizar justiça" - o que se entende por justiça?

\footnotetext{
${ }^{9}$ Essa análise está presente no seguinte trecho do original: "Se trata de Constituciones que no se limitan a establecer competencias o a separar a los poderes públicos, si no que contienen altos niveles de normas "materiales" o sustantivas que condicionan la actuación del Estado por medio de la ordenación de ciertos fines y objetivos".

${ }^{10}$ O principal trecho merece reprodução do original: "La actuación del Tribunal Constitucional Federal alemán al ordenar tempranamente en la década de los 50 la disolución de los partidos neonazis, el trabajo de la Corte Costituzionale italiana para hacer exigibles los derechos sociales previstos en la Constitución de ese país, las sentencias del Tribunal Constitucional español para ir delimitando el modelo de distribución territorial de poder entre el Estado central y las comunidades autónomas, son casos que nos ilustran sobre el papel central que tienen los jueces constitucionales dentro de la consolidación democrática; También en América Latina tenemos ejemplos de jurisdicciones que han estado a la altura de los tiempos que les ha tocado vivir. Son célebres las resoluciones de la Corte Constitucional colombiana al conocer de procesos de acción de tutela por medio de las cuales se mandaron poner drenaje en barrios marginales o través de las que se aseguraba una correcta impartición de justicia dentro de las comunidades indígenas de ese país. También la Sala Constitucional de Costa Rica tiene en su haber varios precedentes que han demostrado la pertinencia de los jueces constitucionales. Los jueces brasileños han logrado salvar vidas ordenando la entrega de medicamentos esenciales para personas sin recursos económicos. En Guatemala el Tribunal Constitucional paró un golpe de Estado que pretendió dar el entonces Presidente Jorge Serrano Elías en 1993. Sobre este último assunto, interessante verificar: LANGUARDIA, Jorge Mario García. Justicia constitucional y defensa de la democracia. El golpe de estado en Guatemala en 1993, Cuestiones constitucionales. Revista Mexicana de Derecho Constitucional, n. 2, México, enero-junio de 2000, p. $3-21$.

${ }^{11}$ Citados por Miguel Carbonell como os principais teóricos, em vários países: "Ronald Dworkin, Robert Alexy, Gustavo Zagrebelsky, Luis Roberto Barroso, Carlos Nino, Luis Prieto Sanchís o el mismo Luigi Ferrajoli han servido no solamente para comprender las nuevas constituciones y las nuevas prácticas jurisprudenciales, sino también para ayudar a crearlas. De entre los muchos ejemplos que se podrían poner basta citar la enorme influencia de la teoría de los principios y de la técnica de la ponderación de Robert Alexy en las sentencias de la Corte Constitucional de Colombia (que, por cierto, ha desarrollado la mejor jurisprudencia en materia de derechos fundamentales de toda América Latina".
} 
Definir como seria o Judiciário ideal implica em procurar entender o que seja "justiça" que ele busca concretizar. As teorias positivistas tentaram separar o Direito, considerado objetivo, do ideário de "justiça", que é, por essência, axiológico, subjetivo e, por isso, não deveria ser trabalhado pelo Direito. Já as teorias críticas postulam que, sem a justiça é um valor, ela acaba por refletir o valor de um determinado grupo (que esteja no poder).

Os sintomas da crise podem ser verificados em diversos planos: administrativo, com a organização de um aparato burocratizado, moroso e com crescimento constante de demandas; estrutural, com a falta de instalações, pessoal, equipamentos, alto custo operacional e má qualificação de parte de seus técnicos; procedimental, decorrente de uma relação conflituosa com os demais poderes, oriunda também da não consolidação de uma identidade de corpo, mas, principalmente, há uma crise cultural, ou, uma crise de paradigmas do Poder Judiciário que, frente a demandas complexas, que envolvam direitos transindividuais e impliquem na ponderação de princípios muito mais do que na mera subsunção de regras, o magistrado ainda se oriente alguma concepção de direito liberal, normativa e individualista.

Neste sentido, a crise do Poder Judiciário é uma crise no modelo jurisdicional forjados sob o fundamento da Separação de Poderes (mito?).

E, mais que as diversas vertentes da crise apresentada, há duas outras questões, muito mais profundas e de difícil análise: a primeira diz respeito à definição de justiça (ou qual justiça), e a segunda, implícita na problemática anterior, permeia a questão do paradigma adotado para se alcançar esse valor (subjetivo) de justiça.

Num Estado Democrático de Direito, a sujeição do magistrado à norma legal somente deveria ser realizada quando esta estiver em consonância com os imperativos constitucionais.

Assim, o Poder Judiciário, que antes produzia decisões alicerçadas em códigos binários (lícito ou ilícito), hoje busca uma jurisprudência fundamentada em princípios, os quais, necessariamente, são dotados de maior vagueza e amplitude terminológica.

A jurisprudência atual, voltada à consecução de determinados princípios, acaba por provocar uma certa tensão, especialmente quando assume contornos de decisões que "usurpam 
" as competências de outros poderes, ou, mais precisamente, quando "judicializam a política" decidindo uma questão de forma a, possivelmente, gerar uma crise institucional.

Isso acontece, especialmente, quando a sociedade, face à inércia e omissão dos Poderes Legislativo e Executivo, passa a atribuir aos magistrados a função ativa de afirmaçãoconcretização de diversos direitos (de justiça material).

Isso acaba por gerar maior visibilidade ao poder judiciário (ou, ainda, a personificar essa incumbência em alguns de seus membros), do qual se espera que adote a postura de desempenhar uma função transformadora, em que a atividade jurisdicional não se reduza a mera aplicação formal da lei ao caso concreto, mas que, se necessário, corrija seus defeitos, suprima ausências e omissões legislativas, concretizando e buscando a consolidação de direitos sociais, econômicos e culturais (DESCs), efetivando os objetivos traçados na Constituição, especialmente no que tange à justiça social, redução da pobreza e da desigualdade.

No cenário atual, o Poder Judiciário está frente a um dilema: ou traz para si a incumbência de assegurar os DESCs, sob o risco de sofrer forte pressão dos outros Poderes e ser criticado pelo aumento do ativismo e (consequentemente) da judicialização, ou mantém o padrão clássico liberal, da mera aplicação do subsuntiva da norma a caso, e termine sendo criticado por ser um poder sem relevante papel social e subserviente aos demais poderes.

Cremos que, no atendimento de um mínimo existencial, por meio da ponderação de princípios e à custa de uma certa judicialização, não há ideia de liberdade de mercado, proteção da propriedade ou princípio da separação de poderes que se sobreponha a concretização do postulado da dignidade da pessoa humana e de efetivação da justiça social.

\section{REFERÊNCIAS}

BONAVIDES, Paulo. Do Estado Liberal ao Estado Social. 7.ed. 2.tir. São Paulo: Malheiros, 2004. DALLARI, Dalmo de Abreu. Elementos de Teoria Geral do Estado. São Paulo: Saraiva, 2009. p.186.

DELFINO, Lúcio \& ROSSI, Fernando. Interpretação Jurídica e Ideologias: o Escopo da Jurisdição no Estado Democrático de Direito, 2008. Disponível em: 
http://www.tex.pro.br/home/artigos/64-artigos-jun-2008/5972-interpretacao-juridica-eideologias-o-escopo-da-jurisdicao-no-estado-democratico-de-direito. Acesso em 17/08/2014 às 15:42.

ESSER, Josef. "Principio y norma en la elaboración jurisprudencial del derecho privado". Trad. Eduardo Valentí Fiol. Bosch, 1961. pp 24, 88 e 278.

FARIA, José Eduardo. O Poder Judiciário no Brasil: paradoxos, desafios e alternativas. Brasília: Conselho da Justiça Federal, 1995. p. 29-30.

FERREIRA FILHO, Manoel Gonçalves. A Constituição de 1988 e a judicialização da política. Revista da Faculdade de Direito da UFRGS, Porto Alegre, v. 12, 1996. p. 189.

GUERRA Filho, Willis Santiago. Autopoiese do Direito na Sociedade Pós-Moderna. Introdução a uma teoria social sistêmica. Porto Alegre: Livraria do Advogado, 1997. p. 37. HART, Herbert L. A. O conceito de direito. 3. ed. Lisboa: Fundação Calouste Gulbenkian, 1994.

HOURQUERBIE, Fabrice. 'L'empoi de l'argument conséquenctialiste par les juges de common law". HOURQUERBIE, Fabrice. PONTHOREAU, Marie-Claire (orgs.) La motivation des décisions des cours suprêmes et cours constitutionnelles, Bruxelles, Bruylant, 2012. p. 25-47.

LANGUARDIA, Jorge Mario García. Justicia constitucional y defensa de la democracia. El golpe de estado en Guatemala en 1993, Cuestiones constitucionales. Revista Mexicana de Derecho Constitucional, n. 2, México, enero-junio de 2000, p. 3-21.

MONTESQUIEU. Charles de Secondat, Baron de. O Espírito das Leis. 8. ed. rev. São Paulo: Saraiva, 2004, p. 202.

MORAIS, José Luis Bolzan. As funções do Estado Contemporâneo. In: Anuário do programa de Pós-Graduação em Direito. São Leopoldo: Ed. Unisinos, 1999, p.61.

MOREIRA, Eduardo Ribeiro. Neoconstitucionalismo e Teoria da Interpretação. In: MOREIRA, Eduardo Ribeiro (org). 20 ANOS CONSTITUIÇÃO BRASILEIRA São Paulo: Saraiva, 2008. p. 261-277. 
PIRES JR, Paulo Abrão. O Poder Judiciário em busca do Estado Democrático de Direito: crise (diagnóstico e versões) e transição paradigmática. Dissertação de Mestrado: Unisinos, 2000. Texto cedido pelo autor.

PONTHOREAU, Marie-Claire. L'enigme de la motivation encore et toujours L'eclairage comparatif. In: HOURQUERBIE, Fabrice \& PONTHOREAU, Marie-Claire (orgs.) La motivation des décisions des cours suprêmes et cours constitutionnelles, Bruxelles, Bruylant, 2012. p. 7-8.

RAMÓN CAPELLA, Juan. Fruta Prohibida. Una aproximación histórico-teorética al estudio del derecho e del estado. Madrid: Trotta, 1997.p. 145.

RAMOS, ELIVAL. Ativismo Judicial, São Paulo: Saraiva, 2010. p. 310.

ROCHA, Leonel Severo. Introdução de "Paradoxos da auto-observação. Percursos da teoria jurídica contemporânea. Curitiba: JM, 1997. p. 25-26.

ROSANVALlON, Pierre. A crise do Estado Providência. Goiânia: Editora da UFG; Brasília: Editora da UnB, 1997, p.15 e p. 30.

SANTOS, Boaventura de Sousa. Os Tribunais nas Sociedades Contemporâneas. In: Revista Brasileira de Ciências Sociais, n. 30, ano11, fev, 1996, p. 35-44.

_. Pela mão de Alice: o social e o político na pós-modernidade. São Paulo: Cortez, 1995, p. 165.

STRECK, Lenio Luiz. Hermenêutica jurídica e(m) crise. Porto Alegre: Livraria do Advogado, 2000, p. 24.

STRECK, Lenio Luiz \& MORAIS, José Luis Bolzan. Ciência Política e Teoria Geral do Estado. Porto Alegre: Livraria do Advogado, 2000. p.58.

ZANETI Júnior, Hermes. A constitucionalização do processo: o modelo constitucional da justiça brasileira e as relações entre processo e constituição, $2^{a}$ edição. Atlas, 2014. p. 140. 